\title{
UTILIZATION OF BIM IN THE CONSTRUCTION OF A SUBMARINE TUNNEL: A CASE STUDY IN XIAMEN CITY, CHINA
}

\author{
Sai $\mathrm{LI}^{1}$, Zhongjian $\mathrm{ZHANG}^{1^{*}}$, Gang MEI ${ }^{1^{*}}$, Daming $\mathrm{LIN}^{2}$, Jin $\mathrm{YU}^{3}$, \\ Renke QIU ${ }^{4}$, Xingju SU${ }^{4}$, Xuechun $\mathrm{LIN}^{4}$, Chonghua LOU ${ }^{4}$ \\ ${ }^{1}$ School of Engineering and Technology, China University of Geosciences (Beijing), Beijing, China \\ ${ }^{2}$ Research Institute of Highway, Ministry of Transport, Beijing, China \\ ${ }^{3}$ School of Civil Engineering, Huaqiao University, Xiamen, China \\ ${ }^{4}$ Supervision Bureau of Traffic Construction Quality and Safety of Fujian Province, Fuzhou, China
}

Received 16 June 2020; accepted 12 October 2020

\begin{abstract}
Building information modeling (BIM) is an emerging technology that can effectively solve the problems of information dispersion, complex personnel management, and lack of construction supervision, which often occur during the construction of tunnel engineering. Taking the construction of Haicang Tunnel in Xiamen, China as a case study, the utilization of BIM technology in the design stage, the construction simulation and operation are demonstrated during the full-life cycle of the project. During the construction of Haicang Tunnel, the technologies of BIM 3D, BIM 4D, BIM $5 \mathrm{D}$, and Cloud Platform are used to make the construction process controllable and to facilitate the implementation and deployment of construction plans. BIM 3D is a visualization method to show the detailed model in the construction. The design is optimized by the navigation collision function of BIM 3D. BIM 4D adds the time schedule into BIM 3D model to show the construction schedule. BIM 5D adds the cost into BIM 4D model to show the construction consumption. The methods of BIM 4D and BIM 5D can assist the engineering management in allocating resources and funds in the project. Cloud Platform is used to effectively implement information management.
\end{abstract}

Keywords: building information modeling (BIM), BIM 4D, BIM 5D, tunnel engineering, construction management, Cloud Platform, visualization.

\section{Introduction}

BIM technology has the characteristics of visualization, simulation, optimization, and collaborative informatization, which can improve the level of engineering construction management especially with higher construction requirements. BIM is an engineering data model based on 3D digital technology that integrates all kinds of relevant information for construction projects and provides a digital expression of the entity and functional characteristics of engineering project facilities (Eastman et al., 2011). It can be used to share and transmit information, which is available over the full-life cycle of the project (Yang, 2013; Zhou et al., 2014).

Tunnel engineering represents the largest scale, the largest number, the most complicated conditions and the fastest-growing construction technology. The construction period of a tunnel project is relatively long due to complex geological conditions and multiple projects' information so that the level of management determines the quality of construction. The utilization process of BIM includes visual modeling of the construction process, which enables the design, construction and operation stages of the tunnel project to be presented in the form of informationbased models, and even provides a 3D visual experience of the tunnel before its construction (He, 2011; Wang \& Ma, 2015). Additionally, the function of engineering information integration can make it easy to implement many operations that are difficult to complete in later stages, such as the refinement of model design, safety of the structure, and system operation (Ryu et al., 2015). The real-time sharing and feedback mechanism of construction progress helps to enhance construction quality and work efficiency, reduce cost and work intensity, and strengthen cooperation between different units (Marzouk \& Abdelaty, 2014). The safety during construction can be ensured by

*Corresponding author. E-mails: zhangzhongjian@cugb.edu.cn; gang.mei@cugb.edu.cn

Copyright $\odot 2021$ The Author(s). Published by Vilnius Gediminas Technical University

This is an Open Access article distributed under the terms of the Creative Commons Attribution License (http://creativecommons.org/licenses/by/4.0/), which permits unrestricted use, distribution, and reproduction in any medium, provided the original author and source are credited. 
a risk identification system using BIM technology (Zhang et al., 2015). Based on its advantageous functions, BIM technology in tunnels has been developing rapidly. Shin et al. (2011) proposed an algorithm to calculate the number of applications of BIM technology in the NATM tunnel construction method and to calculate the number of 3D models based on BIM. Park et al. (2012) developed a new program to calculate tunnel fractures by combining BIM technology with a 3D laser scanner and proposed an efficient and fast data processing process. Ryu et al. (2015) developed a method to predict multiple groups of ground conditions by using simulated Spatial Analysis (a geostatistical method) and to evaluate the tunnel excavation schedule by using BIM technology. Doumbouya et al. (2016) used BIM technology to simulate the deformation monitoring scheme of tunnel drilling during design. It's also used to implement an early structure for a tunnel support (Olawumi \& Chan, 2019).
The BIM technology began to be applied in the engineering field in China since 2002, and its development and utilization were widely in the building and transportation construction. Under the various policies issued by the Ministry of Transportation of the People's Republic of China, it was encouraged to use BIM technology in the field of transportation to urge design and construction personnel to express results and to conduct project management with full participation (Lin et al., 2016). Therefore, BIM technology has been increasingly applied in tunnel projects in China. Table 1 summarizes some projects that used BIM technology in China and their utilization stages.

All of these functions can help improve the efficiency of tunnel construction management, provide an effective and timely solution to the construction schedule when encountering complex geological conditions, and facilitate the control of the economic cost resource consump-

Table 1. Stages and results of BIM utilization in tunnel projects in China

\begin{tabular}{|c|c|c|c|c|}
\hline \multirow{2}{*}{ Project } & \multicolumn{3}{|c|}{ Stages of BIM Utilization } & \multirow{2}{*}{ Results } \\
\hline & Design & Construction & Operation & \\
\hline $\begin{array}{l}\text { Shanxi Shigu Mountain } \\
\text { Tunnel (Li et al., 2014) }\end{array}$ & $\sqrt{ }$ & $\sqrt{ }$ & $\sqrt{ }$ & $\begin{array}{l}\text { Apply the 3D model to export drawings, construction } \\
\text { visualization, technological explanation and simulation }\end{array}$ \\
\hline $\begin{array}{l}\text { Shanxi Qingliang Mountain } \\
\text { Tunnel (Xu, 2015) }\end{array}$ & $\sqrt{ }$ & & & Improve design quality and management \\
\hline $\begin{array}{l}\text { Fuzhou Xingu Mountain Tunnel } \\
\text { (Dai, 2015) }\end{array}$ & $\sqrt{ }$ & $\sqrt{ }$ & & Generate a 3D model with geological information \\
\hline $\begin{array}{l}\text { Shenzhen Metro Line } 9 \\
\text { (Jiang et al., 2016) }\end{array}$ & $\sqrt{ }$ & $\sqrt{ }$ & & $\begin{array}{l}\text { Establish an installation engineering 3D model and } \\
\text { construction simulation with a visualization model }\end{array}$ \\
\hline $\begin{array}{l}\text { Tianjin Metro Line } 6 \text { Shield } \\
\text { Tunnel (Chang, 2016) }\end{array}$ & $\sqrt{ }$ & $\sqrt{ }$ & & $\begin{array}{l}\text { 4D simulation of construction, statistics of engineering } \\
\text { quantities }\end{array}$ \\
\hline $\begin{array}{l}\text { Zhejiang Zizhi Tunnel } \\
\text { (Zheng \& Chen, 2016) }\end{array}$ & $\sqrt{ }$ & $\sqrt{ }$ & & Use of 3D model to refine the steel bar's pattern \\
\hline $\begin{array}{l}\text { Liaoning Lijialiang Tunnel } \\
\text { (Wang, 2016) }\end{array}$ & $\sqrt{ }$ & & & $\begin{array}{l}\text { Establish the BIM model and calculate the project's } \\
\text { quantities }\end{array}$ \\
\hline $\begin{array}{l}\text { Shanghai South Hongmei } \\
\text { Road Tunnel (Zhang, 2016) }\end{array}$ & $\sqrt{ }$ & $\sqrt{ }$ & & $\begin{array}{l}\text { Optimize the simulation of construction of the } \\
\text { subsidiary structure }\end{array}$ \\
\hline $\begin{array}{l}\text { Shanghai Metro Line } 12 \text { (Cheng } \\
\text { et al., 2016) }\end{array}$ & & $\sqrt{ }$ & & Simulate construction and management \\
\hline $\begin{array}{l}\text { Shanghai Yanjiang Channel } \\
\text { Yuejiang Tunnel (Liu et al., 2016) }\end{array}$ & $\sqrt{ }$ & $\sqrt{ }$ & & Optimize the construction of the bridge structure \\
\hline $\begin{array}{l}\text { Shanghai Yanggao South } \\
\text { Road Tunnel (Zhu, 2016) }\end{array}$ & $\sqrt{ }$ & & & $\begin{array}{l}\text { Establish 3D model to assist the main and subsidiary } \\
\text { structures }\end{array}$ \\
\hline $\begin{array}{l}\text { Shanghai Dalian Road Tunnel (Shi } \\
\text { et al., 2016) }\end{array}$ & & & $\sqrt{ }$ & Apply navigation function to assist management \\
\hline $\begin{array}{l}\text { Zhejiang Lingxia Tunnel (Huang } \\
\text { et al., 2017) }\end{array}$ & & & $\sqrt{ }$ & Assist the maintenance in operation level \\
\hline $\begin{array}{l}\text { Lanzhou Metro Line } 1 \text { Donggang } \\
\text { Station } \\
\text { (Zhang et al., 2017) }\end{array}$ & $\sqrt{ }$ & $\sqrt{ }$ & & $\begin{array}{l}\text { The 3D model is established to assist the simulation of } \\
\text { construction }\end{array}$ \\
\hline $\begin{array}{l}\text { Fujian Phoenix Mountain Tunnel } \\
\text { (Ouyang, 2017) }\end{array}$ & $\sqrt{ }$ & & & Accurately model complex structural parts \\
\hline $\begin{array}{l}\text { Guizhou Zhaiguan Tunnel (Che \& } \\
\text { Mao, 2018) }\end{array}$ & $\sqrt{ }$ & & & Generate the main structure's design model \\
\hline $\begin{array}{l}\text { Hunan Sangzhi Tunnel } \\
\text { (Xu \& Zhao, 2018) }\end{array}$ & $\sqrt{ }$ & $\sqrt{ }$ & & $\begin{array}{l}\text { Utilize the BIM model in the design and construction } \\
\text { stages }\end{array}$ \\
\hline
\end{tabular}


tion of the project. Therefore, the utilization of BIM in the construction of tunnel engineering can give full play to its advantages of integrated information platform and full-life cycle management throughout the project (Song et al., 2019).

However, the utilization of BIM technology in tunnel engineering is mainly focused on $3 \mathrm{D}$ visualization model with a lack of unified modeling standards, which results in most of the models being unable to be reused. What's more, in terms of tunnel construction management, there are few on-site cases using BIM in the full-life cycle of the project. More practical utilization is needed to promote the development of BIM technology, and the application of BIM in engineering construction is still developing and is more focused on progress simulation. A growing number of scholars and designers are trying to improve its functions, combining BIM technology with engineering examples to assist project management.

In this case study, BIM technology is applied to the construction process of the Haicang Submarine Tunnel, and research into BIM visualization via $3 \mathrm{D}$ modeling, construction process simulation via BIM $4 \mathrm{D}$ and BIM $5 \mathrm{D}$, also the construction collaborative management are carried out to show the application process of BIM in the project. The structure of this paper is organized as follows: Section 1 describes the utilization of BIM3D visualization model of the case study in Xiamen. Then in Section 2, the simulation of construction is carried out via BIM technology, and in Section 3, the function of collaborative management platform for construction is illustrated. In Section 4, the paper discusses the advantages of the utilization of BIM . In the last section, a conclusion is drawn to summarize the function of BIM and its development in the future.

\section{Utilization of BIM3D in the construction of Haicang Tunnel}

\subsection{Brief introduction to Haicang Tunnel}

Haicang Tunnel is located in Xiamen City, Fujian Province, China, and represents a second cross-sea tunnel case (Figure 1). The project mainly includes left and right line tunnels, service tunnels, and other facilities. The tunnel starts near the intersection of Maqing Road and Haicang Avenue (starting from left BZK11+525.3 and right BYK11+519.7), going from west to east; crosses Shigushan Interchange and then ends at Xiamen Island. The total length of the tunnel is $7.1 \mathrm{~km}, 6.4 \mathrm{~km}$ of which is undersea. The deepest part of the tunnel is approximately $72.6 \mathrm{~m}$ below sea level.

Section A1 is selected for the case study in this paper with a total length of $3374.7 \mathrm{~m}$ for the left line and $3407.1 \mathrm{~m}$ for the right line. The service tunnel has a total length of $2796 \mathrm{~m}$. Furthermore, there are 9 pedestrian crossings and 4 driving crossings. The cross-sea channel of the Haicang project adopts the form of two highway tunnels with one service tunnel. Small spacing wiring is used for both the entrance and the island section of the tunnel, and separate wiring is used for the submarine section.

The driving tunnel was excavated in a concealed way. The location adopting open-cut methods has a rich water content in stratums and is mainly composed of miscellaneous filling soil on the surface, a silt layer, pore water in the completely weathering layer and fissure water in the strong weathered rock layer (Figure 2). For this reason, some dewatering wells are set in the pit to drain the underground water to ensure the stability of the slope during excavation. A retaining structure with the form of a bored pile is adopted due to the deep depth of the excavation.

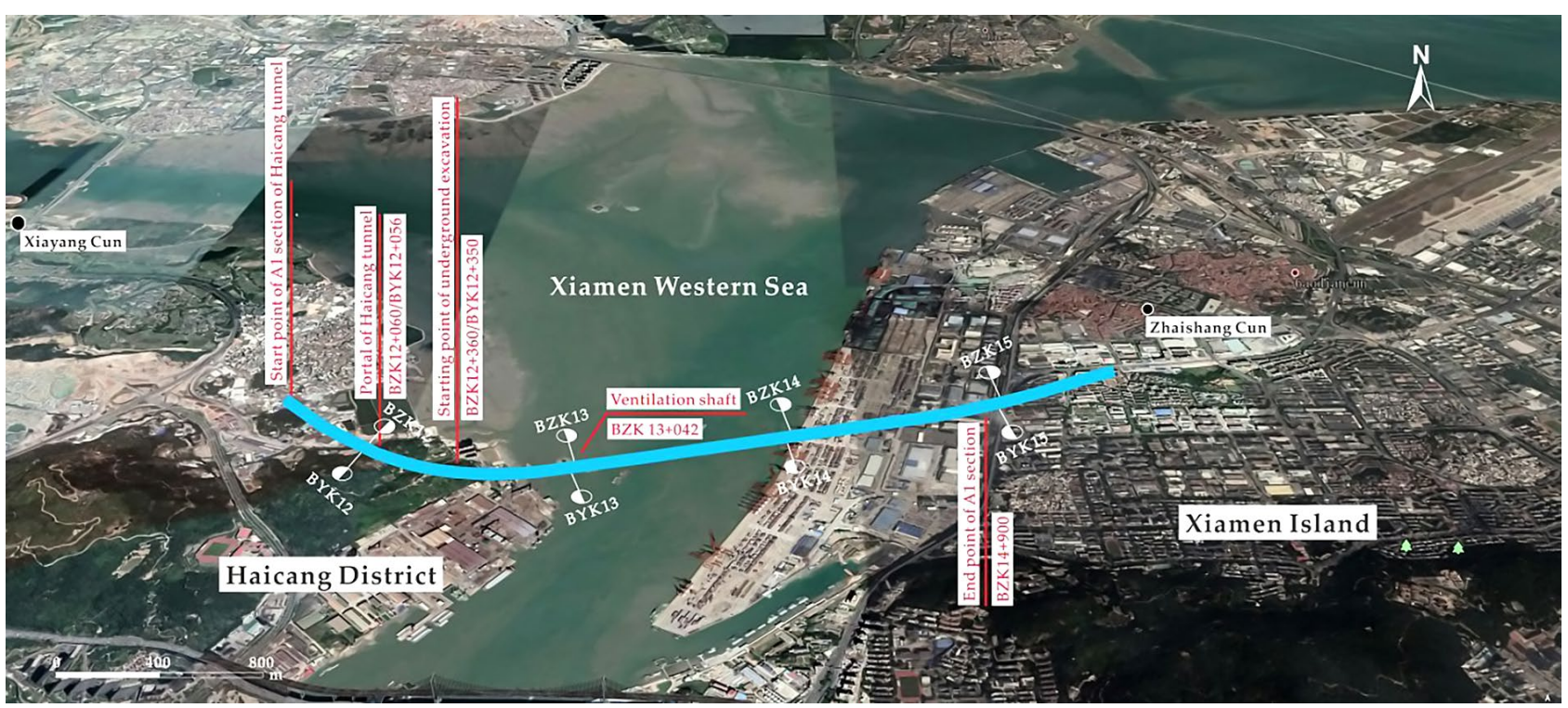

Figure 1. Haicang Tunnel is located in Xiamen city, Fujian Province, Southeast China 


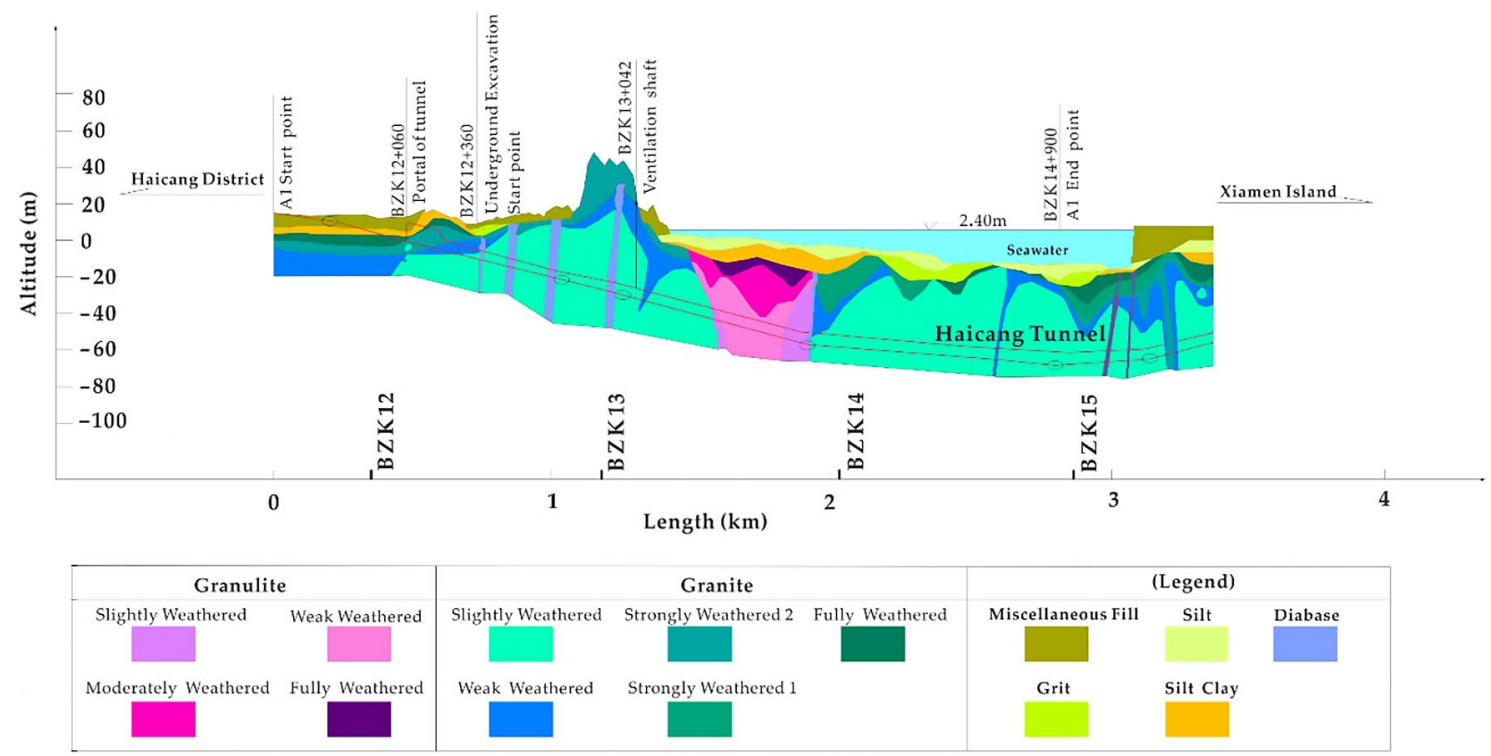

Figure 2. Geographical profile of section A1 of Haicang Tunnel to display the geological conditions

The construction management of this tunnel project is particularly important as the project line passes through the weathering channel and a fault, which makes the construction difficult.

The construction of Haicang Tunnel involves the submarine part, thus, the control of progress and construction technology requirements are much higher. In the process of site construction, there exists an unreasonable drawing design that leads to cross collision between service tunnel and sidewalk. Some construction progress is also behind in schedule, which delays the overall resource allocation and deployment.

\subsection{Establishment of the BIM $3 D$ model}

The first step of applying BIM technology to tunnel construction is to establish a $3 \mathrm{D}$ visualization model. On this basis, the following steps can be performed to apply the visualization model and assist with the construction simulation. First, the model component library, including the left, right and service tunnels, is constructed and assembled. Then, the layout drawing is imported into the modeling software, and the components are assembled as an entity according to the location layout to complete the overall model. The attribute information is added to the model and combined with the geological information.

In this case study, we choose Autodesk Revit to build the 3D model. The tunnel engineering is distributed in a strip, and different construction methods are used for different mileage sections, which is different from a house building model. Therefore, the component family model library is established for each part of the tunnel project. A libraries are a carrier of information about the components and parameters that make up a project. The elements are grouped according to their purpose or graphi- cal similarity. In a family, parts or attributes of different primitives may have different values, but the definitions of the attributes are the same. According to the different supporting parameters of the tunnel, the whole structure of the tunnel is classified and managed.

Taking the tunnel concrete structure as an example, the method of BIM3D modeling is presented. Firstly, a profile family file is established, and the CAD drawings of tunnel opening cross-section are imported to draw the outline of the tunnel. The second step is to use the lofting tool to stretch the contour along the track line of the tunnel to obtain the $3 \mathrm{D}$ visualization model of the tunnel concrete components (Figure 3 ). One by one, the family library model is created using the metric model tool and the built-in component family library of 3D models as follows (Figure 4).

The method of naming the construction components is unified according to the primary lining and secondary lining for the convenience of management, as the format of "serial number - construction method - surrounding rock grade - length - type - mileage start and stop pile number" (Figure 5a). Then, the properties information of the components are added (Figure 5b).

The drawing of the route plan of the Haicang Tunnel project is imported to determine the layout position of the 3D model (Figure 6). The components are assembled to build the chamber and the highway crossing of the tunnel. Then, a Boolean subtraction is performed using the pedestrian crossing tunnel and the intersection of the left and right sides of the tunnel. The self-made family file is loaded into the project file to generate the main tunnel with each part of the section along the track. Then, a complete model is generated by assembling and integrating different tunnel structures. 


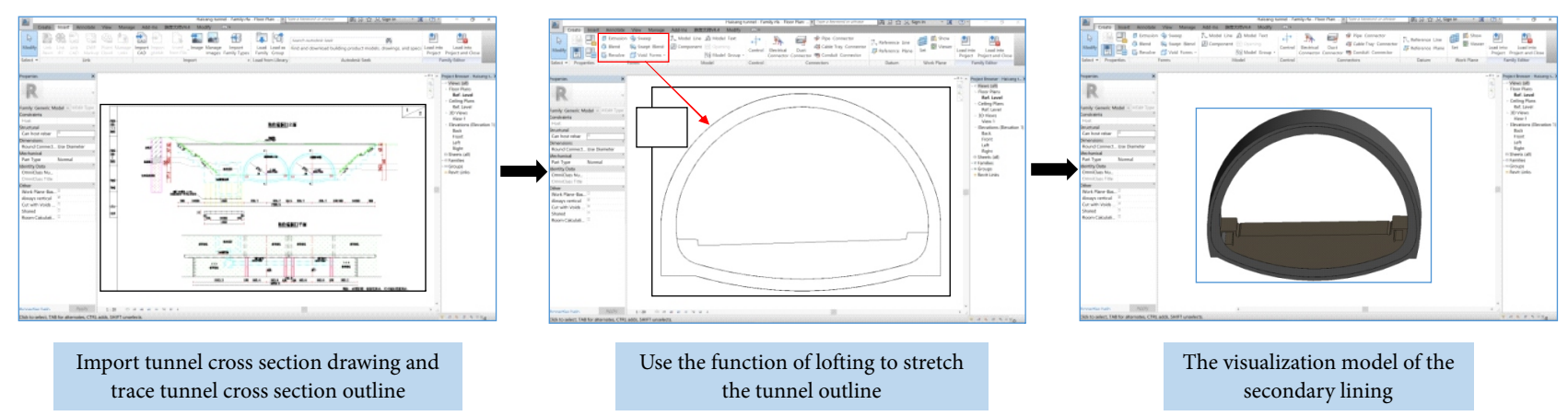

Figure 3. The method of establishing a component model

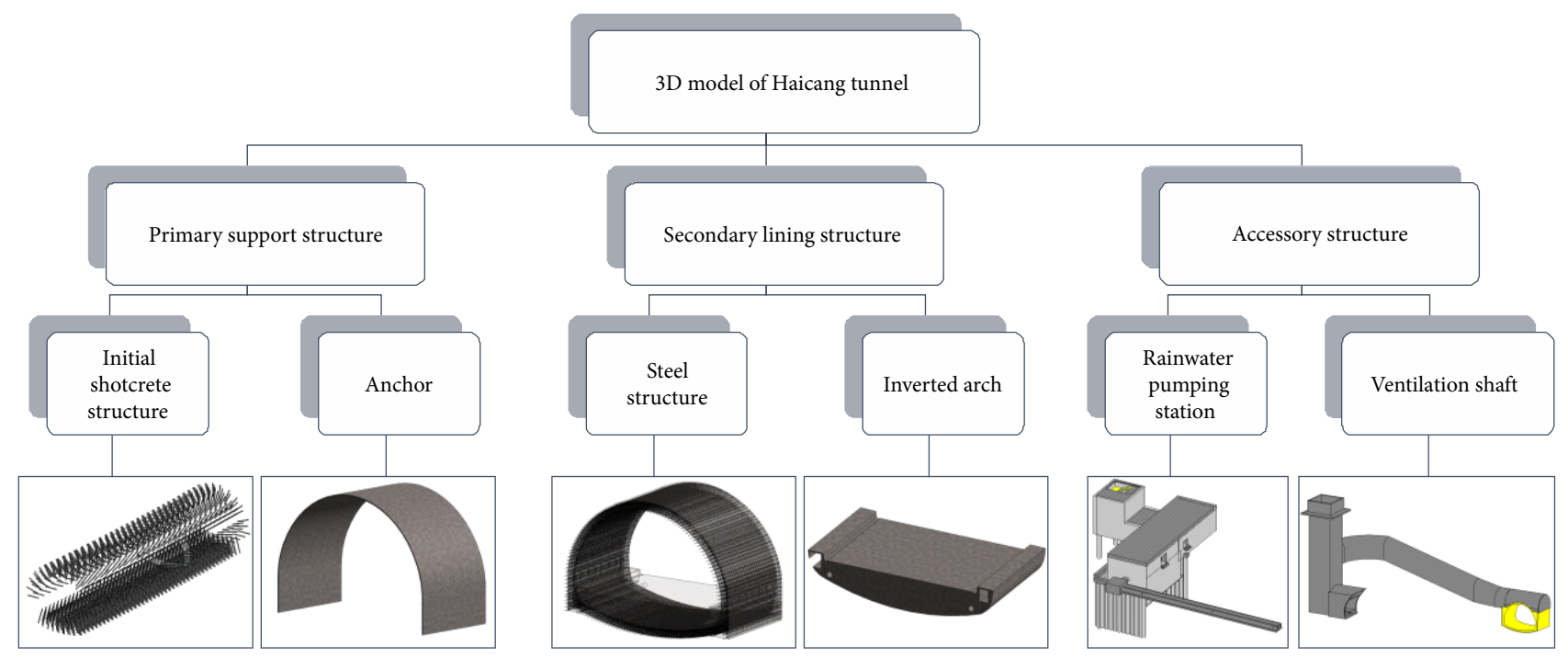

Figure 4. The component models under the classification

a)

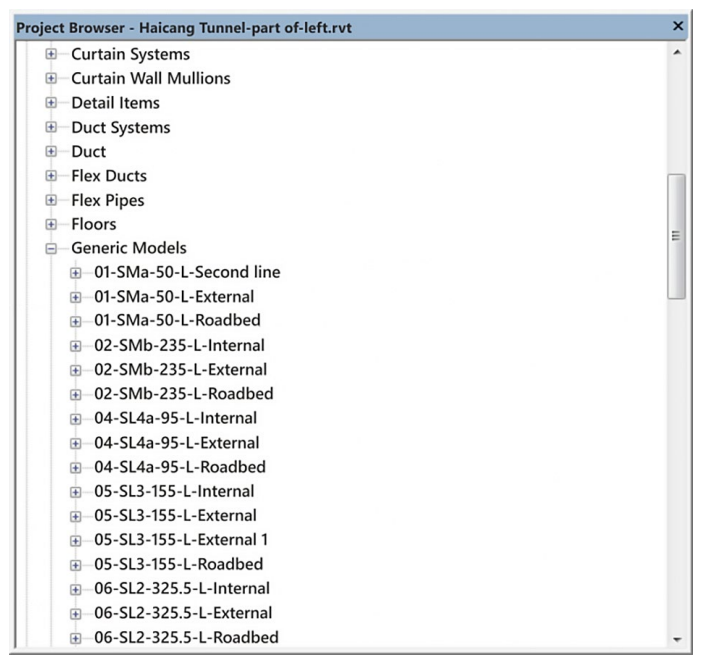

b)

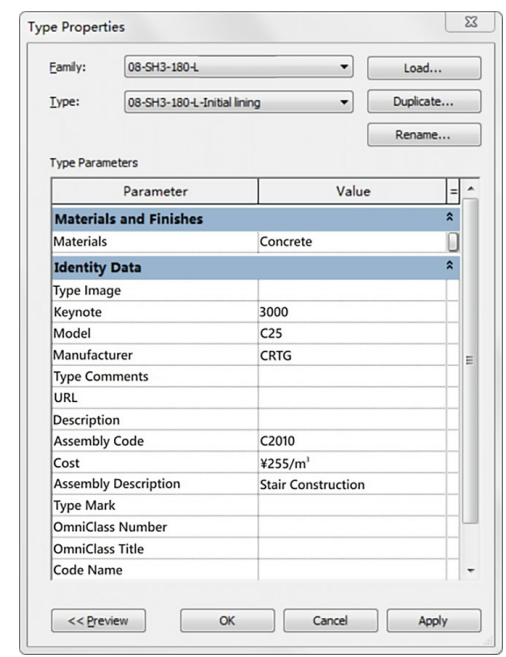

Figure 5. a - The naming pattern and classification of components shown in the Revit software; $\mathrm{b}$ - The type properties show the detailed information of components

\subsection{Utilization of the BIM 3D model for visualization and navigation}

After completing the engineering design, a quick and convenient check for errors is an effective measure to ensure the accuracy of the construction and avoid construction rework. Additionally, this step is helpful for professional personnel to explain the construction method, engineering characteristics, and other technical points, that is, to provide a technical explanation. All of these features are straightforward and easy to display, which facilitates the 


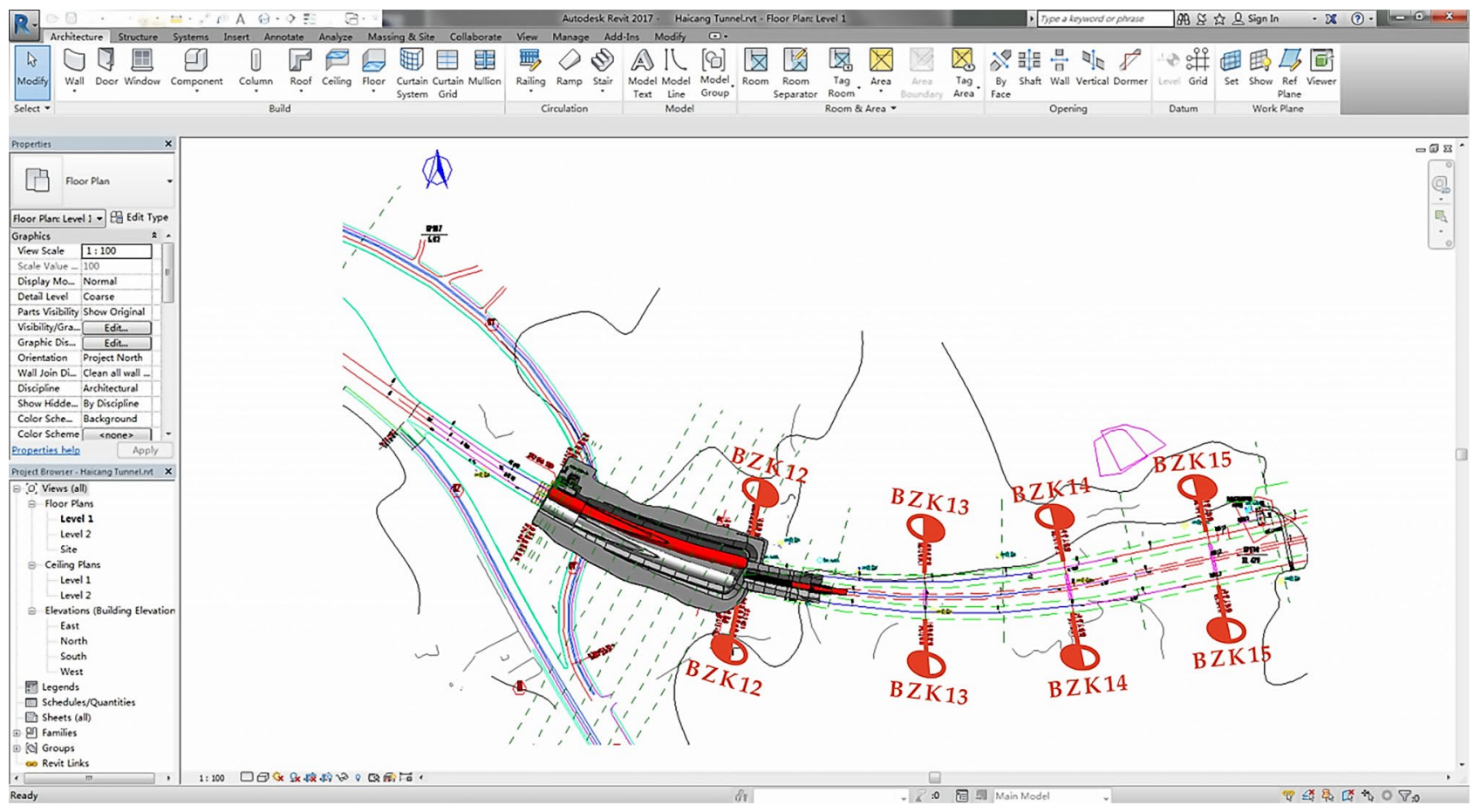

Figure 6. The tunnel model assembled in Revit software

a)

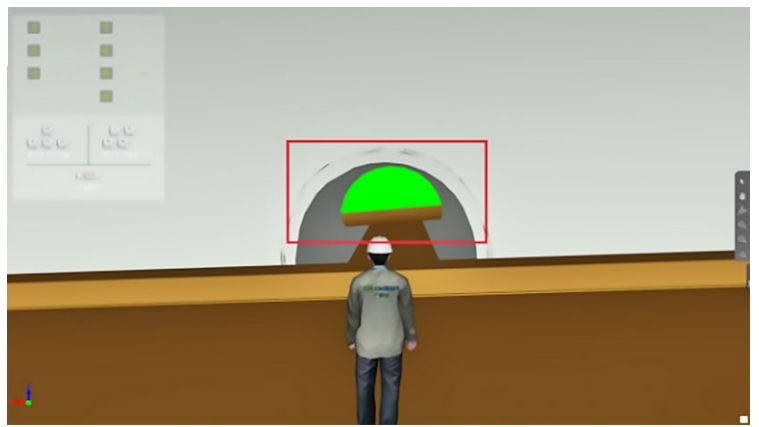

b)

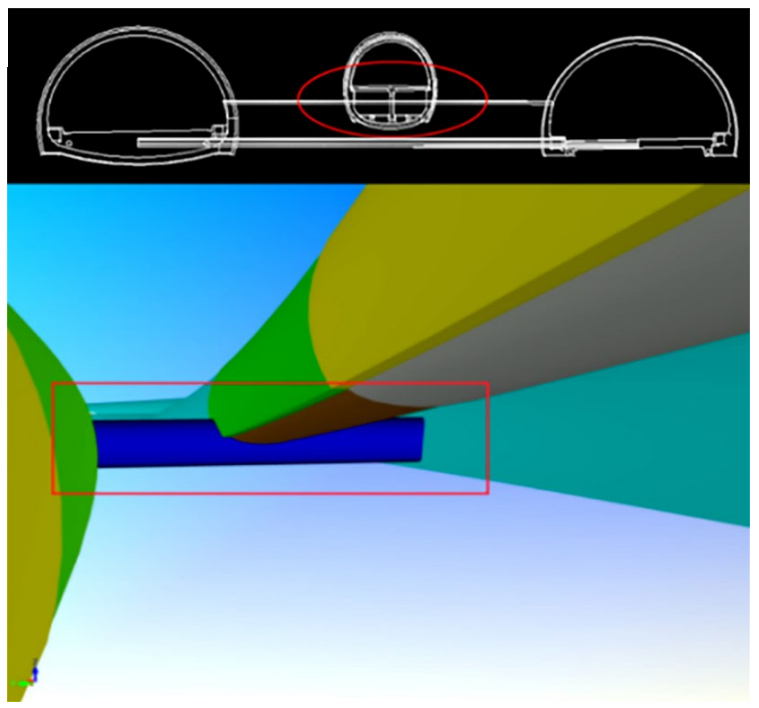

Figure 7. Use BIM 3D model to realize roaming collision detection: $\mathrm{a}$ - $\mathrm{a}$ structural error is detected; $\mathrm{b}$ - the BIM 3D model and 2D drawing are compared to find design errors and modify them scientific organization of the construction to avoid quality and safety problems. The BIM 3D visualization model realizes these functions. Therefore, in its utilization, the model can directly express the situation of the construction project through visualization technology and assist with the project.

The $3 \mathrm{D}$ model is imported into the Glodon software to recheck the design using the method of navigation. Glodon software is used to conduct a dynamic roaming inspection of the BIM model of the tunnel. Through a functional operation, the height and gravity options of the characters are set; then, the simulation of the characters walking forward, backward, leftward, and rightward is controlled, and the internal and external structural conditions of the tunnel are inspected (Figure $7 \mathrm{a}$ ). Through the navigation collision inspection, it is found that there are errors of no. 1 crossing tunnel and air-to-air crossing of service tunnel (Figure $7 \mathrm{~b}$ ) in the drawings of Haicang Tunnel. If the construction is carried out in accordance with this drawing, it will cause rework and affect the progress of subsequent projects.

In the construction of Haicang Tunnel, due to its proximity to the sea floor, the secondary lining structure bears the overlaying load of earth pressure and high water pressure, which is more difficult to construct and requires higher bearing capacity than ordinary tunnel engineering. Therefore, the construction technology of reinforced concrete members is stricter. The use of drawings for technical disclosure is likely to cause errors in the lashing and binding of steel bars in key parts.

The traditional technological explanation of tunnel construction is usually expressed in words and 2D drawings (Figure 8a). Construction mistakes are often caused 
ข
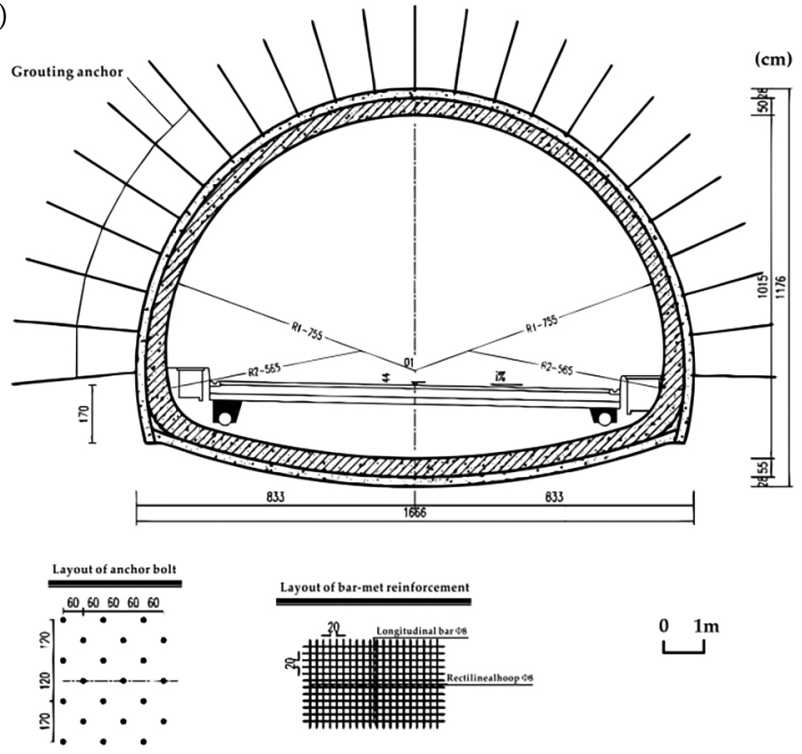

b)

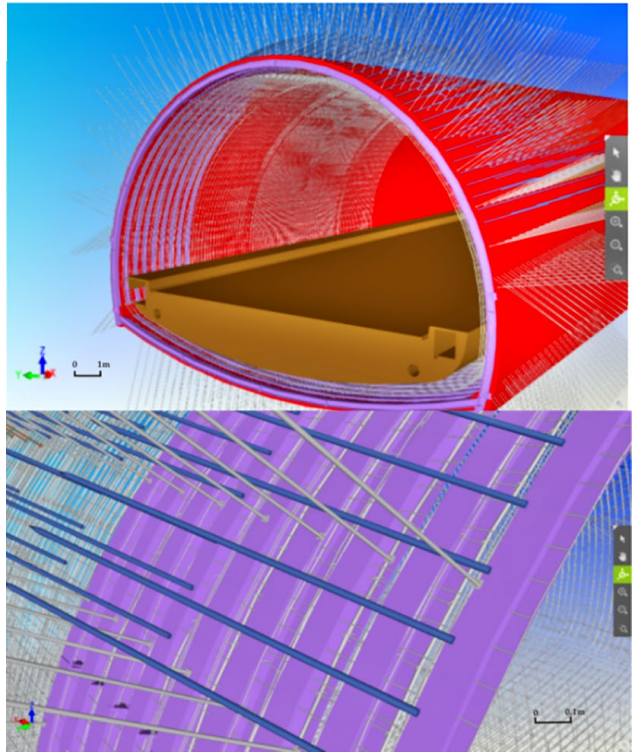

Figure 8. Methods of technological explanation in construction: a - a traditional 2D drawing only shows the entity briefly; $\mathrm{b}-\mathrm{a} 3 \mathrm{D}$ visualization model shows more details and vividly expresses the entity

due to inadequate understanding by construction personnel, resulting in unnecessary rework and even delays in construction. Compared with the traditional way of showing $2 \mathrm{D}$ drawings, the $3 \mathrm{D}$ tunnel space model displayed by BIM technology can truly project the tunnel construction structure (Figure 8b). This model is convenient for constructors to express opinions accurately and vividly and is easy to understand and discuss.

The utilization of BIM technology can facilitate the technological explanation in an intuitive form with the aid of a 3D model. It is possible to see the details of the intersection node of the tunnel, the specific arrangement of the supporting reinforcements and the size of the components, namely, the intersection of construction engineering and visualization technology. This approach makes it easier for the constructor to understand and guide construction, improves the efficiency of the technological explanation to relevant personnel, and avoids mistakes (Figure 9).

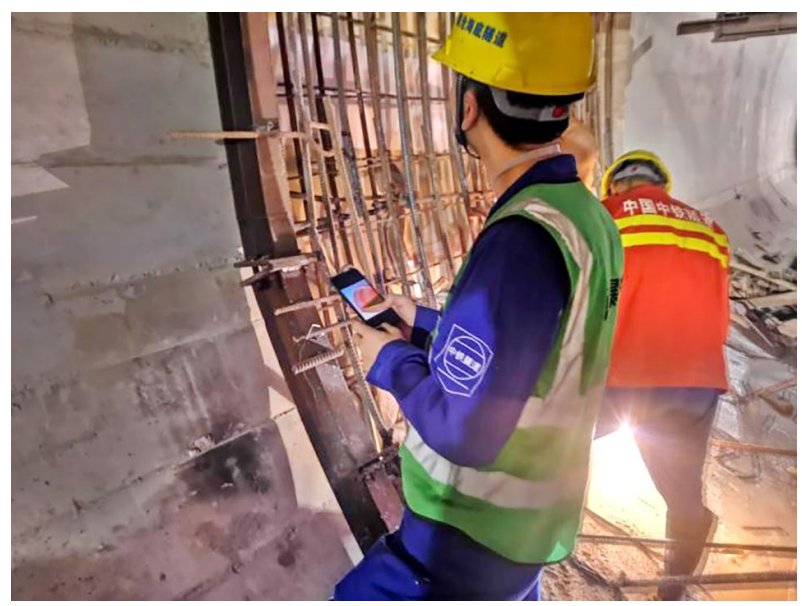

Figure 9. The worker on site is conducting a technological explanation according to the BIM 3D model displayed on a phone

\section{Utilization of the BIM 4D and BIM 5D method to simulate the construction process}

BIM technology integrates information related to the construction of a project and expresses building entities and functions digitally. BIM technology is used to simulate the construction process and can control the construction progress in real time and allocate resources. More concepts are raised on the basis of BIM 3D with the development of BIM technology. The concept of BIM $4 \mathrm{D}$ adds a time schedule into BIM 3D modeling, and on this basis, the cost information is added into BIM 4D modeling, yielding BIM 5D. BIM 5D is a new technology that can be used to simulate the construction process and apply the construction scheme dynamically from the perspective of 5D.

Project management based on the BIM model Cloud Platform enables all parties of a construction project to share project information and progress in a timely manner and to simulate the construction process effectively.

\subsection{Simulate a construction schedule using a BIM 4D model}

The traditional construction method is easy to cause a series of problems such as the construction period delay and, sometimes even cause rework. Especially during the construction of Haicang Tunnel, the seabed part needs higher level of construction method, thus the dynamic construction progress control is particularly important.

According to the overall construction plan developed by the constructor, through connecting with the BIM 3D model, BIM 4D added the time schedule into BIM 3D model, thus a construction simulation is carried out to provide a visual communication tool to optimize the construction schedule. The visual expression of the construction project is conducive to adjusting and controlling the project schedule in a timely manner. 
By applying BIM 4D technology to a tunnel project, the construction progress is visualized and dynamically simulated, and the time nodes are connected accurately. A source control table can be generated to help the project manager predict the construction layout plan of key nodes in the project as well as the material cost required in each time period; thus, all parties can find problems in advance and optimize the plan timely.

Different time periods can be set to display the progress of the tunnel construction (Figure 10). The actual progress can be compared with the planned progress, and they can be distinguished in different colors. The mileage section marked in red indicates that the construction has not been carried out as scheduled, the mileage section marked in yellow indicates that the construction is in progress, and the section marked in grey indicates that the sections of the construction are completed. It can be seen that the excavation footage on the left side of the tunnel is too slow, which affects the construction progress. With the help of this dynamic BIM 4D simulation technology, we can achieve macro control of construction progress and allow timely adjustments by the management personnel.

\subsection{Simulate the construction cost using the BIM 5D model}

The functions of BIM 5D model contain the control of time schedule and cost, especially emphasis on the cost control. The cost control determines the construction efficiency; the total costs of the material input and consumption are the decisive factors. The construction of Haicang Tunnel has difficult and high technical requirements. The material control also has a key impact on the progress. During the process of construction, there exists a problem that the amount of concrete does not conform to the reality, which affects the control of the cost and will cause the delay of the construction period.

The Glodon software is used to count the quantity, cost, and resource consumption of project materials to guide the materials' supply and procurement plan. Personnel can check and count consumption at any time to make the audit process effective and reliable. In this way, quota picking is realized, and the real calculation comparison among quantity, cost, and resource of the project management process is facilitated via BIM 5D model. A time period can be selected to query the software viewport attribute, select the resource and fund curve according to the matching component attribute, and generate a line graph automatically. The comparison between actual consumption and planned consumption can be observed, which is convenient for resource control and cost control.

According to the BIM 5D simulation results, from March 2017 to January 2018, the concrete consumption was planned to be approximately $8380 \mathrm{~m}^{3}$, while the actual consumption was approximately $6075 \mathrm{~m}^{3}$. The actual consumption was approximately $2000 \mathrm{~m}^{3}$ less than the planned consumption. The planned capital consumption was approximately 70 million yuan, while the actual consumption was approximately 40 million yuan. Therefore, the consumption of concrete materials was actually less than the budgeted amount. According to the progress shown (Figure 11), the construction progress of the project is delayed, indicating that the project management personnel needs to adjust the plan.

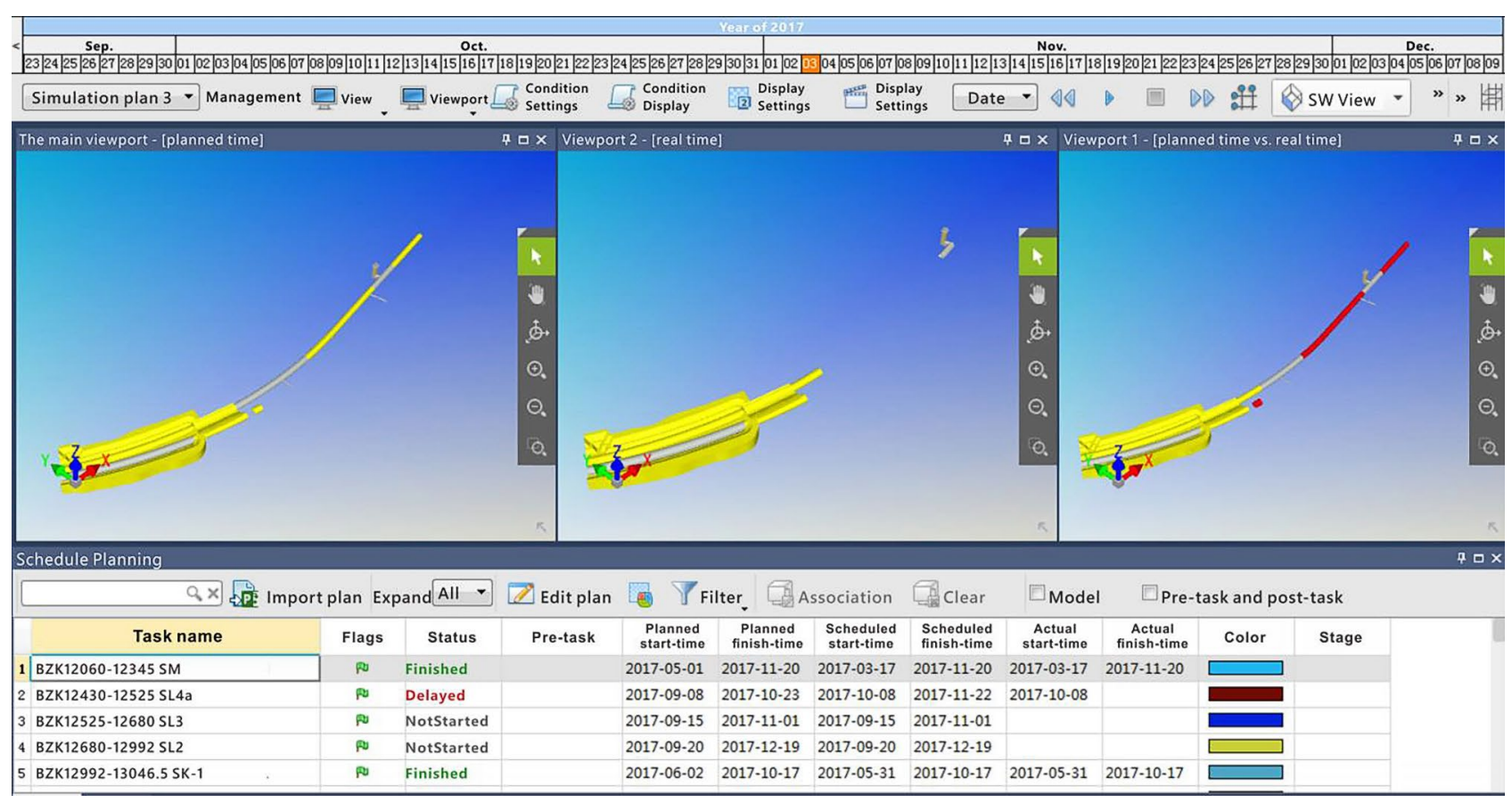

Figure 10. Simulation of the construction process using BIM 4D can realize the management of the time limit of the project 


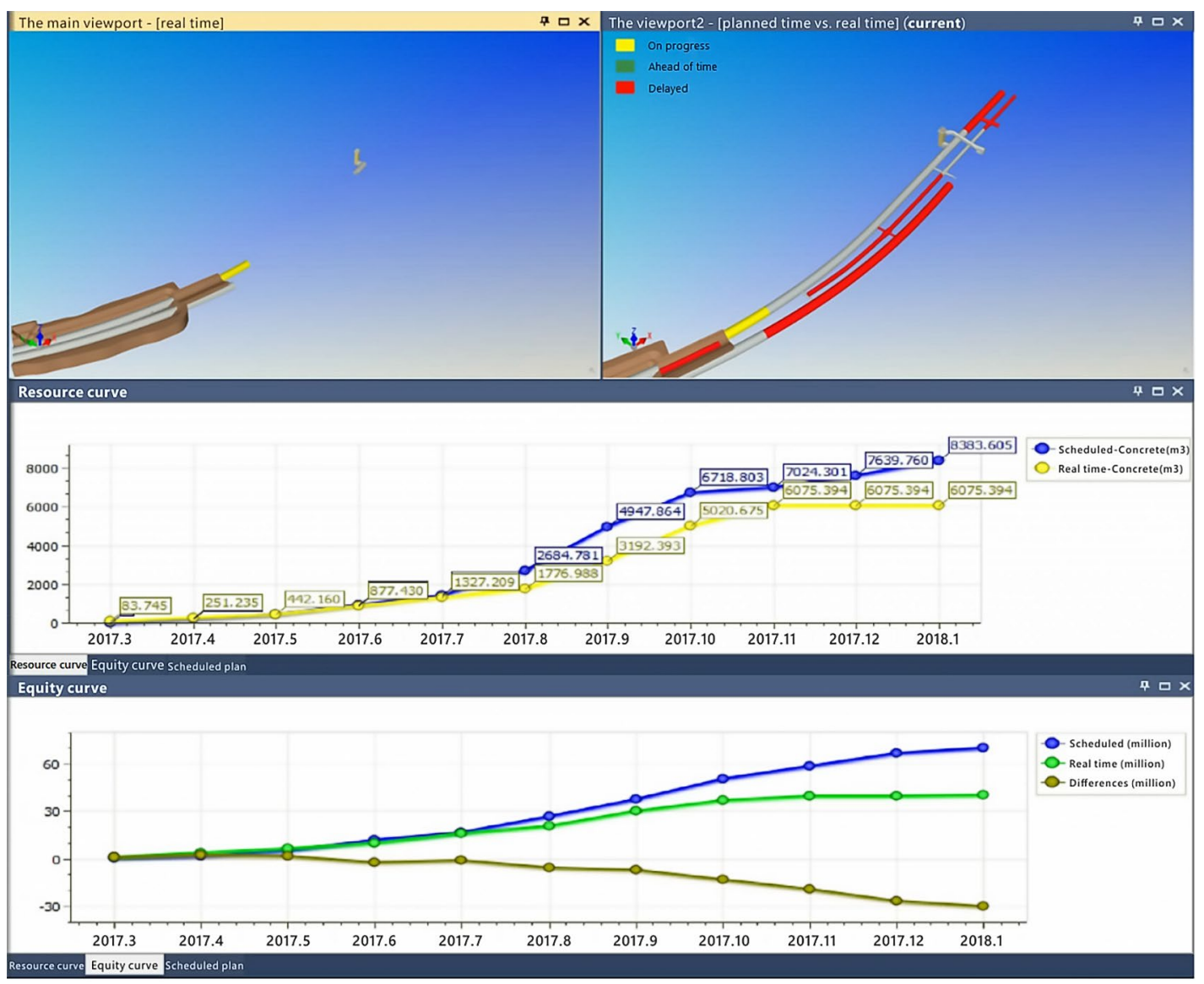

Figure 11. BIM5D software can simulate the construction cost control by comparing the planned and real-time schedules

\section{Manage the construction using the Cloud Platform based on BIM technology}

Cloud Platform collaborative management is carried out for the construction. The field technicians input the tunnel construction progress, quality and safety problems through mobile phones and provide feedback to the Cloud Platform. At the same time, the platform allows the client to input quality and safety problems into a computer, add component information and generate a Quick Response (QR) code containing construction information for tracking. Additionally, data from mobile phones and computers can update to the Cloud synchronously (Figure 12). All of these methods are convenient for checking the projects' progress and information.

The manager can use the BIM project management platform on the website to view the project construction situation in real time, including project information, construction progress quality, and safety information. Meanwhile the platform can set fixed-point patrol objects and track component information. The three client ends share the electronic project data, which can be seen by different personnel through different permission settings.

The Cloud documents function of the Cloud Platform can manage the information of the Haicang Tunnel project and generate a model via BIM, which also contains all the information in the construction process. The library of

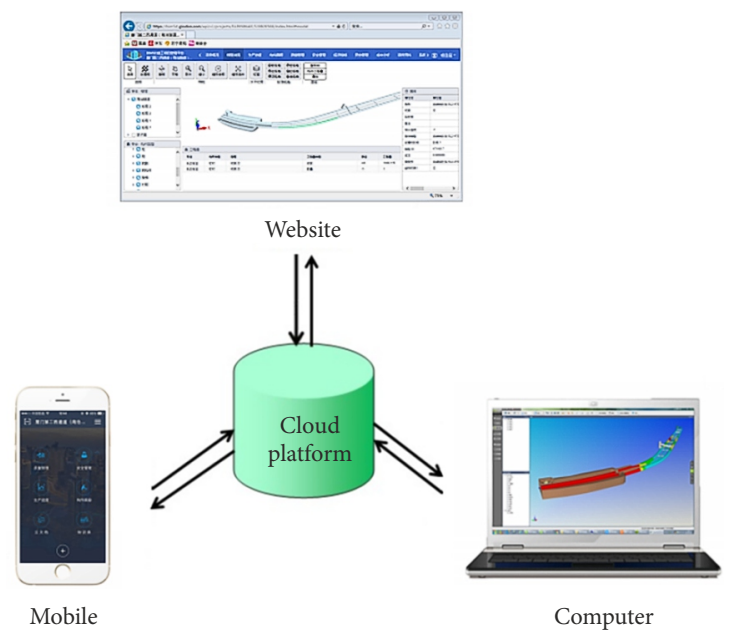

Figure 12. The three clients (mobilelcomputerlwebsite) can exchange project data through the Cloud Platform

component can be checked at anytime and anywhere using the mobile client. The components with complex and difficult construction nodes, all of the data and construction specifications of materials can be scanned through the mobile client. The data files of Haicang Tunnel can be easily uploaded and downloaded, which fully realizes the informatization function of BIM. What's more, if any conflict between the online model and on-site situation appears, the information can be quickly fed back to the 
technical personnel, which can help them timely correct the errors and disclosure of construction.

The photos taken on site can be submitted to the Cloud Platform through the mobile client, which allows the manager to check the progress of the Haicang Tunnel construction image in real time, as well as to record and follow up the on-site progress (Figure 13). The feedback of daily construction node progress can also be linked to the corresponding component section, which realizes the integrated function of BIM technology. For an example, the left line part BZK13+200 mileage of Haicang Tunnel is being excavated at 09:37 am on April $1^{\text {st }}, 2018$, the real time construction process is shown and recorded. The photos taken on site are also attached to display the detailed situation (Figure 13).
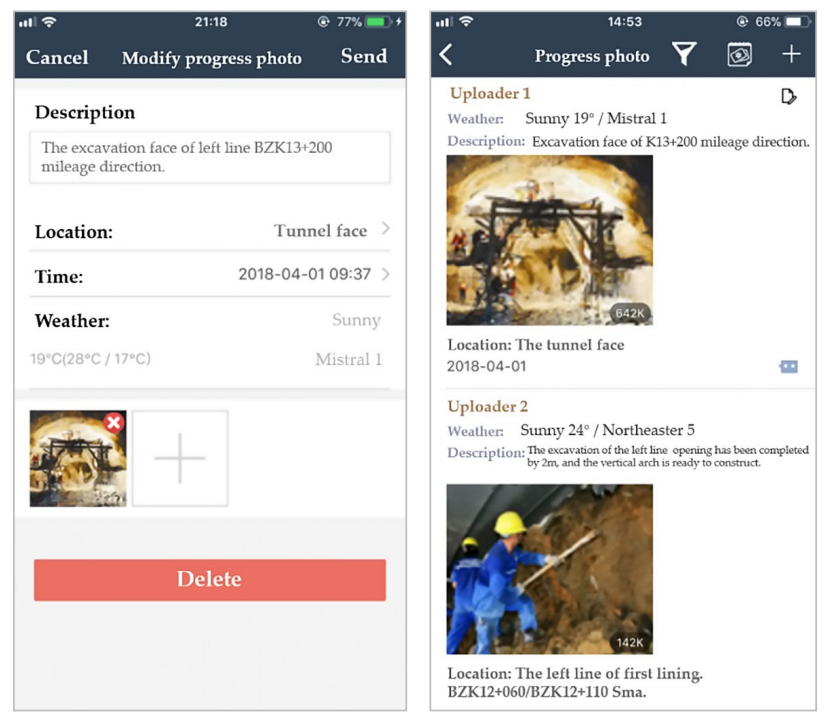

Figure 13. The real time process of construction is shown on the mobile client
Based on the Cloud Platform, the construction management information of Haicang Tunnel can be recorded in an electronic way. The informatization function of BIM is used to support the storage of all relevant information in the construction process, such as drawings, statistical forms, project photos, and technical specifications. The use of the Cloud Platform provides a way of paperless management, which brings more privacy to the data storage. Through setting permissions, different groups people are allowed to have different levels of access to operations such as downloading, viewing, and editing data (Figure 14).

All the above applications give full play to the projects. The QR code posted on site, compared with the original situation of the construction site, makes the formation of a hidden project quality traceable.

The collaborative management platform works as follows:

(1) The model component can be selected at the computer client of the Glodon software, and the information can be added or supplemented by editing element properties or linking the electronic version of construction files.

(2) A QR code can be generated. This QR code gives access to the information of the component material and person in charge at any part of the tunnel model (Figure 15).

(3) The QR code can be posted at the corresponding location of the tunnel on site, and the personnel can scan the code through Wechat or the BIM5D application to see the detailed information.

Thus, the traceability of tunnel construction quality and realization of monitoring and supervision of the whole construction process of Haicang Tunnel can be achieved.

For the quality and safety problems on the tunnel construction site, a mobile terminal can be used for feedback

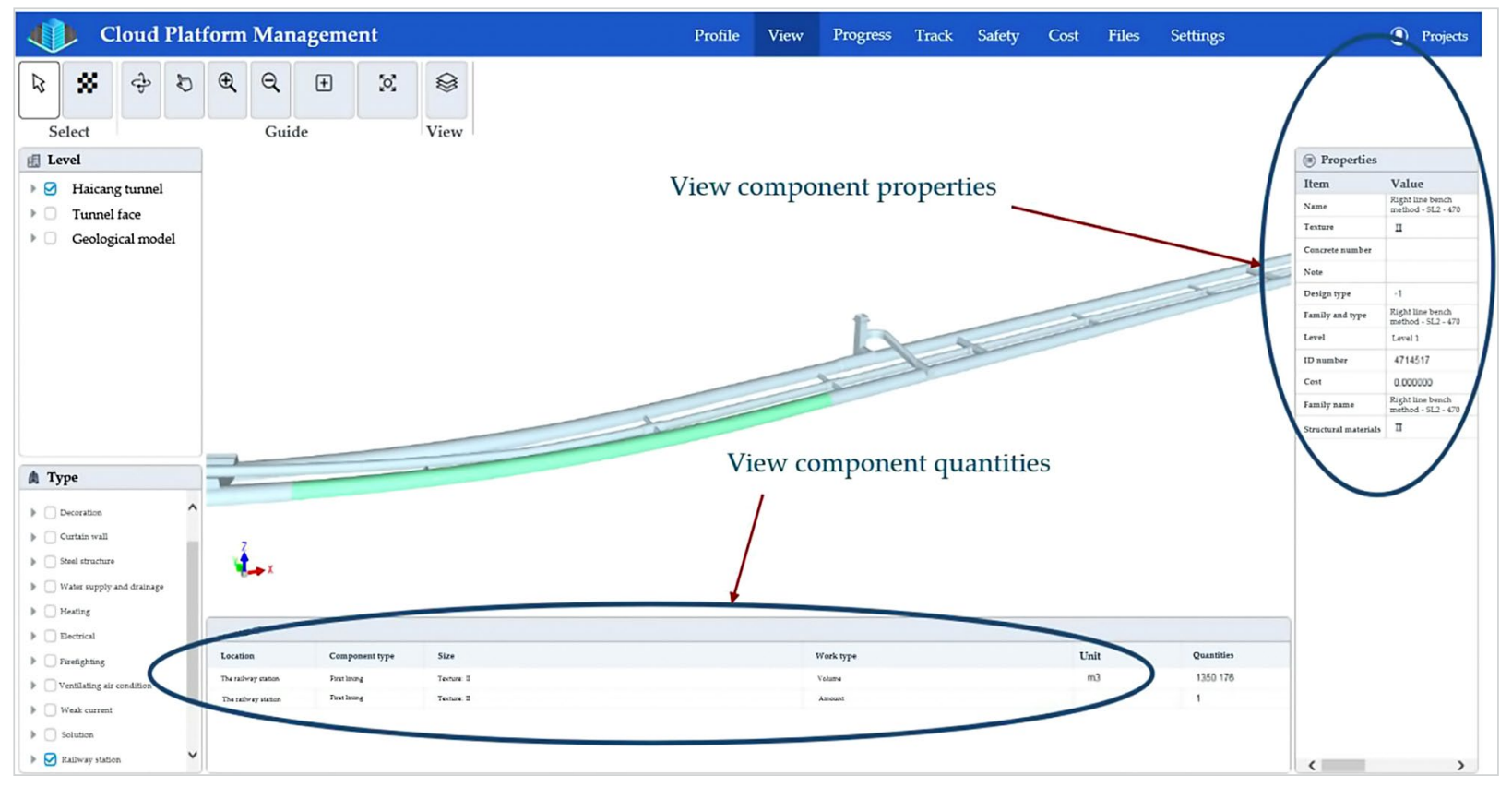

Figure 14. Online browse model to view detailed properties such as component quantity 
(Figure 16). On the construction site, the terminal plays an important role in ensuring the quality and safety of the construction of tunnel by uploading relevant problems and evaluating the level of quality and safety problems through mobile terminal operation (Figure 16). The quality problems and statistical data can be viewed in real time on the mobile terminal, and the rating provided can help solve the problems. Safety management can be realized through a quick feedback method: once a hidden problem is found on site, workers can upload information of the situation and mark the severity level on the mobile phone application immediately. Then, the record can be shown to all departments in time to assist in decision making. The constructor can identify the problems found on-site in the application, evaluate the quality and safety level by level, and indicate the priority level to help solve the issues.

\section{Discussion}

In the case study of the Haicang Tunnel construction described in this paper, different functions of BIM technology are applied in different stages of the construction to optimize the management of the construction of the project. BIM technology is based on 3D modeling and can be applied over the full-life cycle of the project. The BIM $3 \mathrm{D}$ visualization model can vividly express the overall perspective of the construction project. In this way, it can help a constructor carry out technological explanations efficiently and avoid communication deviations. With the simulation and management of construction via BIM 4D and BIM 5D technology, all participators can cooperate together to integrate information and electronically record the information, which improves the efficiency of project

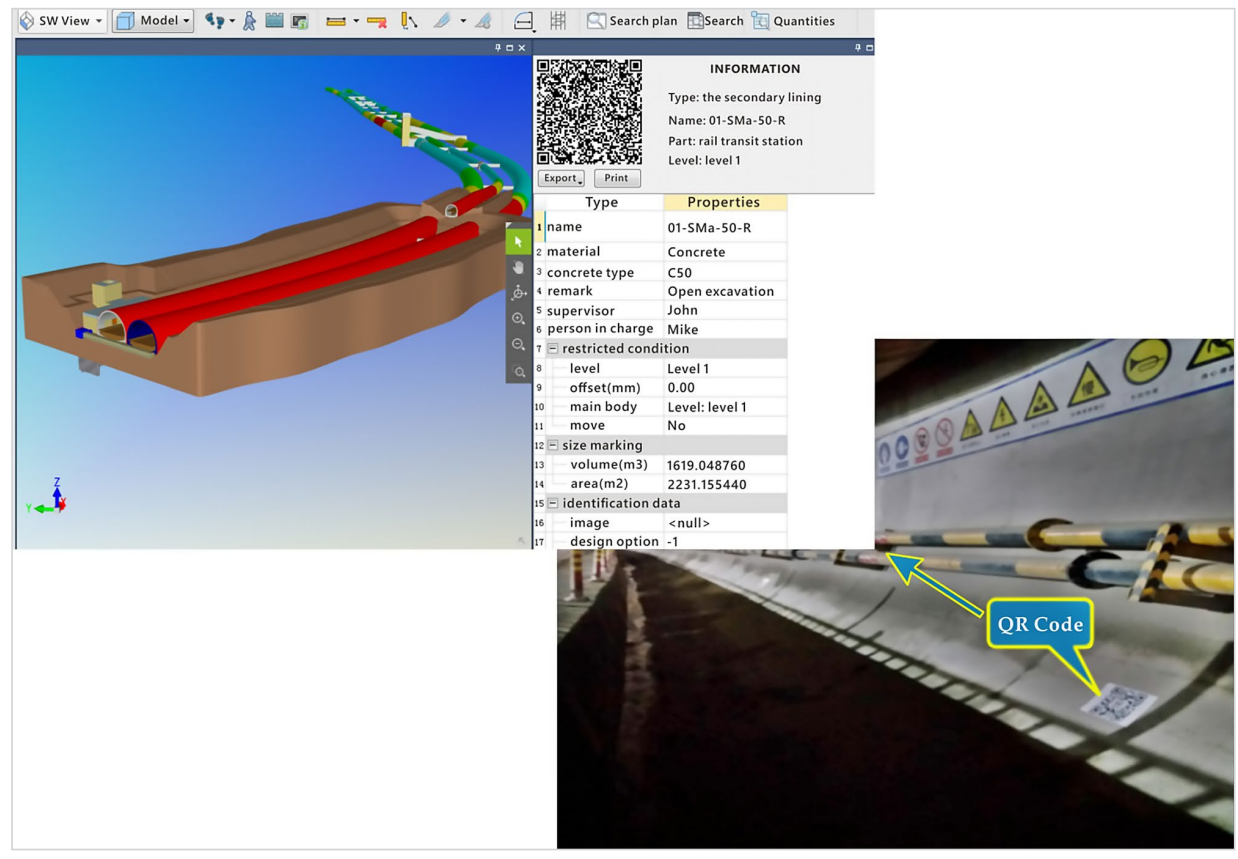

Figure 15. Post a QR code on site containing the construction information for the component

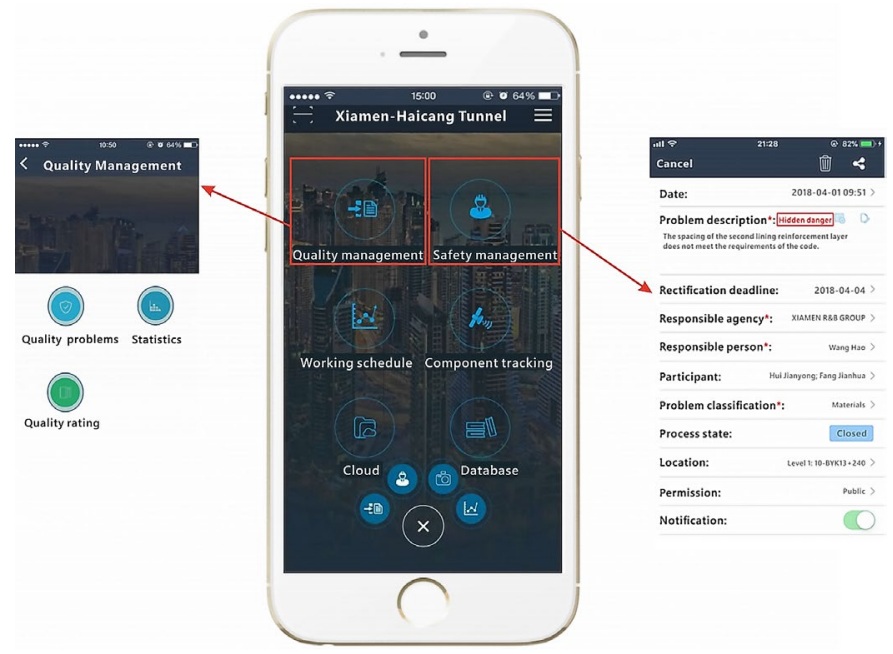

Figure 16. The mobile application is conveniently used for quality supervision and safety management, which provides exact and rapid feedback 
management, control cost resource consumption, and supervise construction quality. The approach of the Cloud Platform truly achieves the goal of convenient and efficient engineering information management.

The innovation of this paper lies in the utilization of BIM 3D, BIM 4D, and BIM 5D technology in the project construction, including construction technical assistance and progress control. Especially in the construction part, the $\mathrm{QR}$ code is posted on the components to show detailed information and assist the site personnel to work, which is a rare or even non-existent measure on the project site. In the whole process of the Haicang Tunnel construction, the utilization functions of BIM in each engineering stage are demonstrated in detail, which promote the development of BIM.

However, for the utilization of BIM technology in tunnel engineering is in the primary stage, the overall information of the BIM model cannot be completely transferred in the construction management stage. There are still some problems, such as the lack of a standard regulation for the data storage format, lack of a component database, and lack of a standard that can be applied in the process of construction. In particular, all BIM software has poor interaction compatibility and lacks an interface. For examples, in the case study of the construction of Haicang Tunnel, we establish a geological model to display the grades of the rock surrounding the tunnel and its geological conditions around. After establishing the tunnel model, the geological model of Haicang Tunnel is created through the longitudinal section of the tunnel and is integrated into the $3 \mathrm{D}$ geological model for viewing. But under circumstance of the complex surrounding submarine environment, the geological model can't be well interfaced with the BIM model, which leads to the lack of geological condition display. In the future, we will strive to combine the geological model with BIM model to expand the utilization level of BIM technology, and make it more convenient to serve more engineering projects.

Currently, BIM is also combining with other technologies such as the Internet of Things (Mei et al., 2020) and gradually collecting information through sensors, laser scanning codes, and so on. Therefore, the platform can more accurately identify, locate, track, monitor, and manage project equipment, facilities and resources.

\section{Conclusions}

Through the case study of the construction of Haicang Tunnel, we achieve several utilizations of BIM in tunnel construction. The following conclusions can be drawn: (1) in the design stage, the model component library is built based on BIM, and the 3D visualization model of the tunnel is completed; (2) visual disclosure is carried out using the $3 \mathrm{D}$ model to express the construction process vividly, which applies the visualization model; (3) constructors can use BIM 4D technology to simulate the time schedule and use BIM 5D technology to simulate the cost schedule, all of which can effectively control the construction pro- cess; (4) the collaborative Cloud Platform is used to implement information management for tunnel construction.

Utilizing the above-mentioned methods in BIM technology makes the construction progress dynamic and controllable, which is convenient for the implementation and deployment of the construction scheme and greatly improves the work efficiency of the construction project. At present, BIM is also combining with advanced technologies such as artificial intelligence, virtual reality, and Internet of Things. All of these can promote the construction of tunnels fully realize informatization, digitalization, and intellectualization in the bright future of engineering.

\section{Acknowledgements}

This work was supported by the Transportation Science and Technology Project of Fujian Province (No. 2016072) and National Natural Science Foundation of China (No. 41602329). The authors thank Tongrui Zhang of Shenyang City University and Shenyang Huayu Architectural Design Co. Ltd for offering software. The authors are grateful to the anonymous reviewers for the careful checking of the details and for helpful comments that improved this paper.

\section{Funding}

This work was supported by the Transportation Science and Technology Project of Fujian Province (No. 2016072) and National Natural Science Foundation of China (No. 41602329).

\section{Author contributions}

All authors have contributions to this article. All authors have read and agree to the published version of the manuscript. Conceptualization and supervision, Z. Zhang, G. Mei and D. Lin; methodology, S. Li and J. Yu; formal analysis, S. Li; investigation, R. Qiu and X. Su; resources and data curation, X. Lin and C. Lou; writing - original draft preparation, S. Li; writing - review and editing, Z. Zhang and G. Mei.

\section{Disclosure statement}

Authors declare that they have not any competing financial, professional, or personal interests from other parties.

\section{References}

Chang, J. J. (2016). Application of BIM technology in subway tunnel construction. Scientific \& Technical Information of Gansu, 45(6), 35-42.

Che, G. Y., \& Mao, W. D. (2018). Analysis on Revit+Dynamo parameterized tunnel model construction system. Journal of Highway and Transportation Research and Development, 14(4), 246-248.

Cheng, Y. T., Teng, L., Yu, G., \& Hu, M. (2016). Research on construction schedule management of municipal engineering based on BIM. Construction Technology, 45(S1), 768-771. 
Dai, L. F. (2015). Study on current applications and problems of BIM in tunnel engineering. Railway Standard Design, 59, 99-103.

Doumbouya, L., Guan, C. S., Deng, S. X., \& Gao, G. P. (2016). Collinear force and frequency analysis of a viaduct pile foundation construction project: A case study on the application of BIM technology [Conference presentation]. 15th International Scientific Conference: Engineering for Rural Development, Jelgava, Latvia.

Eastman, C., Teicholz, P., Sacks, R., \& Liston, K. (2011). BIM handbook: A guide to building information modeling for owners, managers, designers, engineers and contractors (2 ed.). Wiley.

He, G. P. (2011). Development strategy and pattern of building information modeling in China (version 1). Journal of Information Technology in Civil Engineering and Architecture, 3, 114-118.

Huang, T., Chen, L. J., Shi, P. X., \& Yu, C. C. (2017). Design and development of BIM-based operation and maintenance system of highway tunnel. Tunnel Construction, 37(1), 48-55.

Jiang, Z. F., Mao, Q. S., Du, F., \& Zhang, L. (2016). Discussion on application and effect of Building Information Modeling (BIM) technology in design of Shenzhen metro line No. 9. Tunnel Construction, 36(4), 433-438.

Li, L., Ma, T. T., \& Yuan, Z. (2014). Application of BIM technology in railway tunnel design. Railway Technical Innovation, $5,45-48$.

Lin, Y.-C., Lee, H.-Y., Yang, I.-T. (2016). Developing as-built BIM model process management system for general contractors: A case study. Journal of Civil Engineering and Management, 22(5), 608-621. https://doi.org/10.3846/13923730.2014.914081

Liu, Z., Yuan, S. Q., \& Huang, H. (2016). BIM technology application in Shanghai riverside passageway \& river-crossing tunnel project. Journal of Information Technology in Civil Engineering and Architecture, 8(3), 20-25.

Marzouk, M., \& Abdelaty, A. (2014). Monitoring thermal comfort in subways using building information modeling. Energy and Buildings, 84, 252-257.

https://doi.org/10.1016/j.enbuild.2014.08.006

Mei, G., Xu, N., Qin, J., Wang, B., Qi, P. (2020). A survey of Internet of Things (IoT) for geohazard prevention: Applications, technologies, and challenges. IEEE Internet of Things Journal, 7(5), 4371-4386. https://doi.org/10.1109/JIOT.2019.2952593

Olawumi, T. O., \& Chan, D. W. M. (2019). Building information modelling and project information management framework for construction projects. Journal of Civil Engineering and Management, 25(1), 53-75.

https://doi.org/10.3846/jcem.2019.7841

Ouyang, Y. (2017). Apply BIM technology to construct threedimensional model accurately of the tunnel entrance. Peak Data Science, 6(6), 72-74.

Park, J. J., Shin, J. C., Hwang, J. H., Lee, K. H., Seo, H., \& Lee, I. M. (2012). Assessment of over / under-break of tunnel utilizing BIM and 3D laser scanner. Journal of Korean Tunnelling and Underground Space Association, 14(4), 437-451.

https://doi.org/10.9711/KTAJ.2012.14.4.437

Ryu, D. W., Kim, J. I., Suh, S., \& Suh, W. (2015). Evaluating risks using simulated annealing and building information modeling. Applied Mathematical Modelling, 39(19), 5925-5935. https://doi.org/10.1016/j.apm.2015.04.024

Shi, Y. Q., Hu, M., \& Wu, H. M. (2016). BIM-based operation and maintenance management of Dalian road tunnel in Shanghai. China Municipal Engineering, 6, 62-64, 68.
Shin, J. C., Baek, Y. I., \& Park, W. T. (2011). Analysis of errors in tunnel quantity estimation with 3D-BIM compared with routine method based 2D. Journal of the Korean Geotechnical Society, 27(8), 63-71. https://doi.org/10.7843/kgs.2011.27.8.063

Song, Z., Shi, G., Wang, J., Wei, H., Wang, T., \& Zhou, G. (2019). Research on management and application of tunnel engineering based on BIM technology. Journal of Civil Engineering and Management, 25(8), 785-797. https://doi.org/10.3846/jcem.2019.11056

Wang, H. (2016). Application of BIM technology in high-speed railway tunnel design. Railway Technical Innovation, 3, 75-79.

Wang, Z. J., \& Ma, A., Z. (2015). BIM technology and its application in the railway tunnel design. Construction Technology, 44, 59-63.

$\mathrm{Xu}, \mathrm{B}$. (2015). Application research of BIM technology in Qingliang tunnel. Railway Technical Innovation, 3, 90-93.

Xu, B., \& Zhao, Q. L. (2018). Application of BIM technology in Sangzhi tunnel of Qian-Zhang-Chang railway. Railway Standard Design, 62(12), 75-79.

Yang, D. L. (2013). Summarize on current situation of foreign BIM implementation. Journal of Information Technology in Civil Engineering \& Architecture, 5, 89-94.

Zhang, T. Y. (2016). Application of BIM technology in the Hongmei South Road Cross-river tunnel engineering. City \& House, 23(8), 24-27.

Zhang, L. M., Wu, X. G., Ding, L. Y., Skibniewski, M. J., \& Lu, Y. J. (2015). BIM-based risk identification system in tunnel construction. Journal of Civil Engineering and Management, 22(4), 529-539. https://doi.org/10.3846/13923730.2015.1023348

Zhang, X. G., Zeng, S. W., \& Wang, P. (2017). Application of BIM techniques to the construction of the Donggang station of the Lanzhou Metro. Modern Tunnelling Technology, 54(2), 46-54.

Zheng, N., \& Chen, C. (2016). Application of BIM technology in the ZI ZHI tunnel project. Journal of Information Technology in Civil Engineering and Architecture, 8(5), 65-70.

Zhou, J. L., Wu, Y. X., \& Yan, X. F. (2014). The technology development of building information modeling in America and enlightenment towards building transformation in China. Science \& Technology Program, 31, 30-33.

Zhu, W. N. (2016). BIM technology application in urban tunnel engineering. Journal of Information Technology in Civil Engineering and Architecture, 8(5), 71-77. 